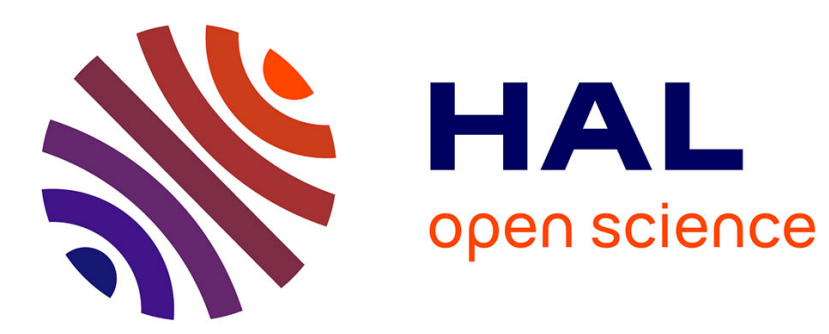

\title{
Highly prolific authors in critical care: which factors influence their scientific output?
}

Emmanuel Weiss, Peter Buhl Hjortrup, Chiara Robba, Audrey de Jong, Julie Helms

\section{- To cite this version:}

Emmanuel Weiss, Peter Buhl Hjortrup, Chiara Robba, Audrey de Jong, Julie Helms. Highly prolific authors in critical care: which factors influence their scientific output?. Intensive Care Medicine, 2019, 45 (11), pp.1673-1675. 10.1007/s00134-019-05744-5 . hal-02270218

\section{HAL Id: hal-02270218 \\ https://hal.science/hal-02270218}

Submitted on 26 Jun 2020

HAL is a multi-disciplinary open access archive for the deposit and dissemination of scientific research documents, whether they are published or not. The documents may come from teaching and research institutions in France or abroad, or from public or private research centers.
L'archive ouverte pluridisciplinaire HAL, est destinée au dépôt et à la diffusion de documents scientifiques de niveau recherche, publiés ou non, émanant des établissements d'enseignement et de recherche français ou étrangers, des laboratoires publics ou privés. 


\title{
Highly prolific authors in critical care: which factors influence their scientific output?
}

\author{
Emmanuel Weiss ${ }^{1,2}$, Peter Buhl Hjortrup ${ }^{3}$, Chiara Robba $^{4}$, Audrey De Jong ${ }^{5}$ and Julie Helms $s^{6,7^{*}}$
}

\section{Dear Editor,}

Researcher's scientific output and relevance are usually measured in terms of number of peer-reviewed publications authored. So far, only a few studies have investigated how environmental and individual factors shape scientific productivity and none of them focused on intensivists. In this issue of Intensive Care Medicine, we describe a population of 78 critical care highly prolific authors having published more than 40 publications within the last 5 years [1]. These authors were surveyed to help analyzing their productivity. In this letter, we report some determinants of the high rate of publications of the 70 highly prolific authors who answered the survey (extended methods are available as ESM).

The author productivity very strongly correlated with the quality of the publications, as assessed by the percentage of top $1 \%$ articles, author numbers of citations and $\mathrm{H}$-index (correlation coefficients $R=0.82,0.92$ and 0.98 , respectively, all $p<0.01$, ESM Fig. 1). The correlation between the overall number of publications and the percentage of publications published in the four major general journals was still strong, but weaker $(R=0.62$, $p<0.01$ ).

Non-European critical care authors published significantly more when considering the median total number of publications [286 (361-189) vs. 197 (278-147) publications, $p=0.03]$, were more cited [8385 (6289-12796) vs. 5009 (3734-8600) citations, $p=0.001]$ and had a higher total H-index [46 (39-53) vs. $36(28-45) p<0.001]$, with oceanic authors being the most prolific (ESM Fig. 2). None of the 78 prolific authors came from Africa or Asia.

\footnotetext{
*Correspondence: julie.helms@chru-strasbourg.fr

${ }^{6}$ Hôpitaux universitaires de Strasbourg, Service de réanimation Médicale,

Nouvel Hôpital Civil, 1, place de l'Hôpital, 67091 Strasbourg Cedex, France
}

Critical care journal choices also differed according to the continent of the authors: while non-Europeans published more in AJRCCM, Chest and Critical Care Medicine, Intensive Care Medicine and Critical Care were more frequently chosen by European authors ( $p<0.01$ each).

Some topics were also more frequently published than the others. For instance, neurology/sedation topic was associated with a lower median number of publications (139 vs. $256, p=0.009$ ). On the other hand, the number of publications in sepsis and infectious disease was higher (279 vs. 206, $p=0.009$ ).

Surprisingly, we found no correlation between author's network strength, measured using VOSviewer, and their productivity $(p=0.42)$. Furthermore, editorial board membership was inversely correlated with the total number of publications (215 vs. 442, $p=0.001$ ). Nevertheless, being the editor (whether editor-in-chief or associate editor) of a journal was associated with an increase in the number of publications in this journal $(p<0.001, \mathrm{ESM}$ Fig. 3). This increase was independent of the number of publications in the four major general journals of the author.

Finally, we investigated the impact of author seniority and of the amount of clinical work ( $>50 \%$ or otherwise) on productivity. The total number of publications of senior authors (defined as more than 20 years of practice) was higher than the one of younger ones $(p<0.001)$. Interestingly, we did not found that a lower time of clinical work (defined as less than $50 \%$ of time) was associated with greater scientific output $(p=0.83)$.

These results were consistent with the principal component analysis (Fig. 1) that identified several factors; either closely related to the number of publications: positive correlation for $\mathrm{H}$-index and number of publications in the big journals, negative correlation for being a journal editor; or not related to the number of publications: link strength, percentage of clinical work $>50 \%$. 


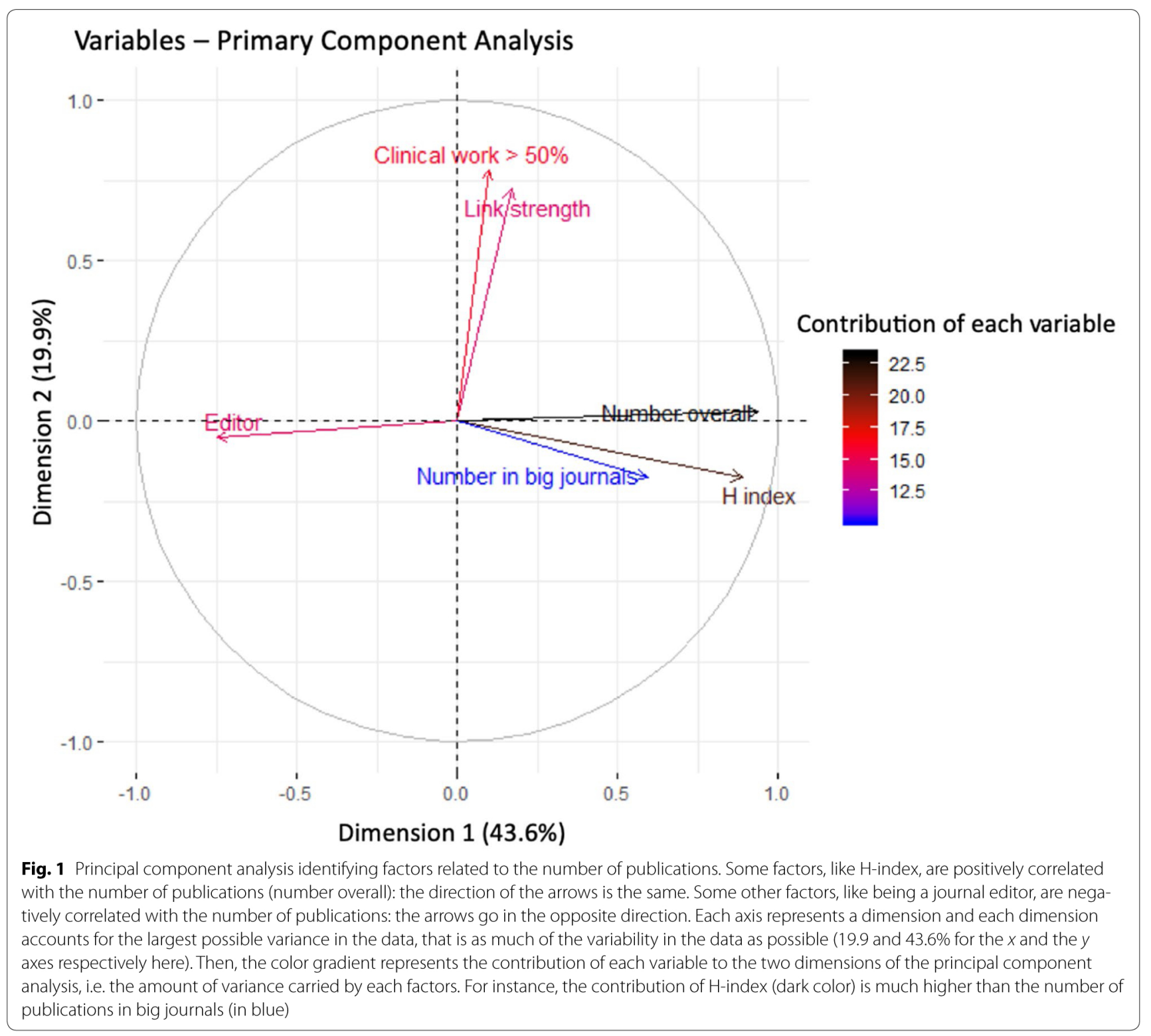

Although commitment to scientific research, hard work, love of research or leadership are some of the main justifications provided by researcher when questioned about their "extreme productivity", Ioannidis et al. argued these would not be strong incentives enough to publish a lot [2]. We therefore looked for other determinants for a high publication rate among critical care authors and tried to objectively find where the devil is hiding.

First, we were reassured to find that productivity correlated with some metrics of publication quality (number of citations or of top 1\% publications), meaning that authors do no prioritize quantity over quality.

Non-European authors published more and were more cited than European fellows. Similar results have already been shown in other medical specialties, but this superiority did not persist when socioeconomic data were taken into account [3]. Interestingly, European authors published more in critical care European journals, and vice versa for non-European ones. This difference may be due to a favoritism of the authors for certain journals, as already described by Ioannidis et al. [2], or to a more frequent rejection of European articles by nonEuropean journal and vice versa, although we do not have such information. Of note, we also found an association between the research topic and the publication rate. Sepsis and antimicrobial therapy were confirmed as critical care blockbusters, while choosing neurology and sedation as topics was less efficient. These results are in agreement with the recent paper published in ICM by Timsit et al. showing that article including septic shock as keywords 
were more downloaded and cited [4]. We also found a significant correlation between the editorial ship and the number of publications in the journal in which the author is or has been an editor, suggesting some degree of favoritism or some sort of "remuneration" for the work accomplished within the journal board. Although some authors previously reported similar results [5], it is not possible to determine whether this is due to bias in the peer review process or selective submission by editors.

We used a specific software for bibliometry (VOSviewer), and identified a strong link between these influent authors [1] that were divided into networks according to their main topics. However, we were not able to demonstrate an impact of this virtuous cycle, as we did not show a correlation between this link strength and the prolificacy of the authors.

Finally, Newman and Jones reminded that authorship is intrinsically linked with career advancement, status and success, and authors will try to maximize these by increasing their publication rate [6]. The higher productivity showed in senior author confirmed this view. Nevertheless, it is interesting to note that it was not due to a lower time dedicated to clinical duties.

\section{Author details}

${ }^{1}$ Department of Anesthesiology and Critical Care, AP-HP, Beaujon Hospital, Clichy, France. ${ }^{2}$ UMR_S 1149 Centre for Research on Inflammation, Inserm/ Université de Paris, Paris, France. ${ }^{3}$ Department of Intensive Care, Copenhagen University Hospital, Rigshospitalet Blegdamsvej 9, 2100 Copenhagen, Denmark. ${ }^{4}$ Department of Anaesthesia and Intensive Care, Policlinico San Martino, IRCCS for Oncology and Neuroscience, Genoa, Italy. ${ }^{5}$ Department of Anesthesia and Intensive Care Unit, Regional University Hospital of Montpellier, PhyMedExp, University of Montpellier, INSERM U1046, CNRS UMR, 9214, St-Eloi Hospital, Montpellier, France. ${ }^{6}$ Hôpitaux universitaires de Strasbourg, Service de réanimation Médicale, Nouvel Hôpital Civil, 1, place de l'Hôpital,
67091 Strasbourg Cedex, France. ${ }^{7}$ ImmunoRhumatologie Moléculaire, INSERM UMR_S1109, LabExTRANSPLANTEX, Centre de Recherche d'Immunologie et d'Hématologie, Faculté de Médecine, Fédération Hospitalo-Universitaire (FHU) OMICARE, Fédération de Médecine Translationnelle de Strasbourg (FMTS), Université de Strasbourg (UNISTRA), Strasbourg, France.

\section{Compliance with ethical standards}

\section{Conflicts of interest}

A De Jong reports personal fees from Baxter and Medtronic-Covidien, and travel reimbursements from Fresenius-Kabi, MSD France, Astellas, Pfizer and Fisher Paykel. J. Helms reports congress and travel reimbursements from Pfizer, Diagnostica Stago, MSD France, Astrazeneca and Gilead Sciences. E. Weiss reports personal fees form Baxter, MSD France and Biomerieux, and travel reimbursements from MSD France and Eumedica. The other authors have no conflict of interest to declare.

\section{References}

1. Robba C, Weiss E, HP B, De Jong A, Helms J (2019) Who are these highly prolific authors in critical care? Intensive Care Med. https://doi. org/10.1007/s00134-019-05743-6

2. Ioannidis JPA, Klavans R, Boyack KW (2018) Thousands of scientists publish a paper every 5 days. Nature 561:167-169

3. Fritzsche FR, Oelrich B, Dietel M, Jung K, Kristiansen G (2008) European and US publications in the 50 highest ranking pathology journals from 2000 to 2006. J Clin Pathol 61:474-481

4. Timsit JF, Citerio G, Lavilloniere M, Perner A, Ruckly S, Bakker J, Bassetti M, Benoit D, Curtis JR, Doig GS, Herridge M, Jaber S, Papazian L, Peters MJ, Singer P, Smith M, Soares M, Torres A, Vieillard-Baron A, Azoulay E (2019) Determinants of downloads and citations for articles published in intensive care medicine. Intensive Care Med 45(7):1058-1060

5. Luty J, Arokiadass SM, Easow JM, Anapreddy JR (2009) Preferential publication of editorial board members in medical specialty journals. J Med Ethics 35:200-202

6. Newman A, Jones R (2006) Authorship of research papers: ethical and professional issues for short-term researchers. J Med Ethics 32:420-423 